\title{
Effect of Hall Current on Unsteady MHD Couette Flow and Heat Transfer of Nanofluids in a Rotating System
}

\author{
Ahmada Omar Ali ${ }^{1, *}$, Oluwole Daniel Makinde ${ }^{2}$, Yaw Nkansah-Gyekye ${ }^{1}$ \\ ${ }^{1}$ Nelson Mandela African Institution of Science and Technology, Arusha, Tanzania \\ ${ }^{2}$ Faculty of Military Science, Stellenbosch University, Saldanha, South Africa \\ Email address: \\ alia@nm-aist.ac.tz (A. O. Ali), makinded@gmail.com (O. D. Makinde), yaw.nkansah-gyekye@nm-aist.ac.tz (Y. Nkansah-Gyekye)
}

\section{To cite this article:}

Ahmada Omar Ali, Oluwole Daniel Makinde, Yaw Nkansah-Gyekye. Effect of Hall Current on Unsteady MHD Couette Flow and Heat Transfer of Nanofluids in a Rotating System. Applied and Computational Mathematics. Vol. 4, No. 4, 2015, pp. 232-244.

doi: $10.11648 /$ j.acm. 20150404.12

\begin{abstract}
The Hall effect on MHD Couette flow and heat transfer between two parallel plates in a rotating channel is investigated. A uniform magnetic field is applied normal to the plates and the flow is induced by the effects of Coriolis force, moving upper plate and the constant pressure gradients. $\mathrm{Cu}$-water, $\mathrm{Al}_{2} \mathrm{O}_{3}$-water and $\mathrm{TiO}_{2}$-water nanofluids are compared for heat transfer performance. The Galerkin approximation and method of lines are employed to tackle the governing non-linear PDEs. The results show that Hall current significantly affects the flow system. The skin friction and Nusselt number profiles are presented graphically and discussed quantitatively.
\end{abstract}

Keywords: Couette Flow, Rotating System, Heat Transfer, Hall Current, Magnetic Field, Nanofluids

\section{Introduction}

Magnetohydrodynamics (MHD) flow with heat transfer is one of the classes of flow in fluid mechanics which has received considerable attention in recent decades. This is due to the advancement of numerous transport processes in engineering and industries where the flow is applied $[1,2]$. Some of the areas where this type of flow is applied are in the extrusion of polymer in the melt spinning process, dispersion of metals, metallurgy, design of MHD pumps and MHD generators $[3,4]$. The performances presented by nanofluids have lead to innovative way of improving the thermophysical properties of working fluids. Choi (1995) [5] experimentally demonstrated the anomalous convective heat transfer enhancement when nanometer-sized particles are suspended in the base fluid. These tiny particles are made up of materials that are chemically stable. Examples of nanoparticles materials are copper $(\mathrm{Cu})$, aluminium oxide $\left(\mathrm{Al}_{2} \mathrm{O}_{3}\right)$ and titanium oxide $\left(\mathrm{TiO}_{2}\right)$, while the base fluids may include water, ethylene-glycol and engine oils [6]. The flow of electrically conducting nanofluids occurs in many industrial and medical applications. These include magnetic drug delivery, power generation etc $[7,8]$.

Sheikholeslami, Gorji-Bandpy, Ganji and Soleimani [9] studied the effect of magnetic field on natural convection in the inclined enclosure filled with nanofluid. They found that Hartmann number and the inclination angle of the enclosure can be control parameters at different Rayleigh number. They also indicated that the presence of magnetic field causes the retarding effect on velocity profile which eventually reduces the heat transfer rate along the boundaries. The effects of magnetic field on convective heat transfer have been investigated by Makinde and Ogulu [10], Olajuwon [11] and Mutuku-Njane and Makinde [12], among others. Moreover, Seth and Mahato [13] put special emphasis on the effect of Hall current on mass and heat transfer characteristics. Other researchers who have reported similar investigation include Ghosh et al. [14], Zaman, Shah, Khan and Javed [15]. Comprehensive reviews of nanofluids convective transports can be found in Mintsa, Roy, Nguyen and Doucet [16], Kakac and Pramuanjaroenkij [17], Trisaksri and Wongwise [18], to mention just a few.

In the present study, we numerically investigate the combined effects of Hall current, magnetic field, viscous dissipation and convective cooling on unsteady hydromagnetic Couette flow and heat transfer of three different types of nanofluids namely: $\mathrm{Cu}$-water, $\mathrm{Al}_{2} \mathrm{O}_{3}$-water and $\mathrm{TiO}_{2}$-water in a rotating system. The pertinent results are presented graphically and discussed quantitatively. 


\section{Mathematical Model}

Consider unsteady, laminar, hydromagnetic Couette flow of a viscous incompressible and electrically conducting nanofluid between two parallel non-conducting plates. A uniform transverse magnetic field $B_{0}$ is applied in the direction parallel to the $z$-axis. The system is in the state of rigid body rotation with uniform angular velocity $\omega$ about an axis normal to the plates as shown in Fig.1.

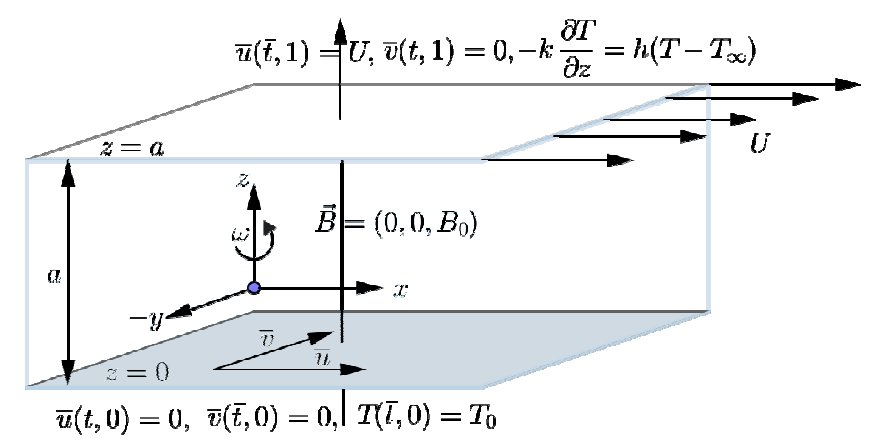

Fig. 1. Schematic diagram of the problem.

The nanofluid flow within the channel is induced due to the combined effects of pressure gradients and the motion of the upper plate. The plates are kept at distance $a$ apart, which is small compared to the characteristic lengths of the plates. The upper plate moves with a uniform velocity $U$ in the $x$ direction on its own plane $(z=a)$. We assume that the plates are of infinite extent in the $x$ and $y$ directions, and therefore, all physical quantities, except pressure, are the functions of $z$ and $\bar{t}$ only. The flow velocity and magnetic field vectors are respectively $q=(\bar{u}, \bar{v}, 0)$ and $B=\left(B_{x}, B_{y}, B_{0}\right)$. Using the modified Buongiorno [19] nanofluid model together with Maxwell nanofluid model for electrical conductivity given in Sheikholeslami et al. [9], the transport equations of the nanofluid in the rotating frame of reference are given by

$$
\begin{gathered}
\frac{\partial \bar{u}}{\partial \bar{t}}=2 \omega \bar{v}-\frac{1}{\rho_{n f}} \frac{\partial \bar{p}}{\partial \bar{x}}+v_{n f} \frac{\partial^{2} \bar{u}}{\partial z^{2}}+\frac{B_{0}}{\rho_{n f} \mu_{e}} \frac{\partial \bar{B}_{x}}{\partial z} \\
\frac{\partial \bar{v}}{\partial \bar{t}}=-2 \omega \bar{u}-\frac{1}{\rho_{n f}} \frac{\partial \bar{p}}{\partial \bar{y}}+v_{n f} \frac{\partial^{2} \bar{v}}{\partial z^{2}}+\frac{B_{0}}{\rho_{n f} \mu_{e}} \frac{\partial \bar{B}_{y}}{\partial z} \\
0=-\frac{1}{\rho_{n f}} \frac{\partial \bar{p}}{\partial z}
\end{gathered}
$$$$
\frac{\partial \bar{B}_{x}}{\partial \bar{t}}=B_{0} \frac{\partial \bar{u}}{\partial z}+\frac{1}{\mu_{e} \sigma_{n f}} \frac{\partial^{2} \bar{B}_{x}}{\partial z^{2}}+\frac{\omega_{e} \tau_{e}}{\sigma_{n f} \mu_{e}} \frac{\partial^{2} \bar{B}_{y}}{\partial z^{2}},
$$$$
\frac{\partial \bar{B}_{y}}{\partial \bar{t}}=B_{0} \frac{\partial \bar{v}}{\partial z}+\frac{1}{\mu_{e} \sigma_{n f}} \frac{\partial^{2} \bar{B}_{y}}{\partial z^{2}}-\frac{\omega_{e} \tau_{e}}{\sigma_{n f} \mu_{e}} \frac{\partial^{2} \bar{B}_{x}}{\partial z^{2}},
$$

with initial and boundary conditions

$$
\left.\begin{array}{l}
\bar{u}(z, 0)=0=\bar{v}(z, 0), \quad T(z, 0)=T_{0}, \bar{B}_{x}(0, z)=0=\bar{B}_{y}(0, z), \\
\bar{u}(0, \bar{t})=0=\bar{v}(0, t), \quad T(0, z)=T_{0}, \bar{B}_{x}(0, \bar{t})=0=\bar{B}_{y}(0, \bar{t}) \\
\bar{u}(a, \bar{t})=U, \bar{v}(a, \bar{t})=0, \quad \frac{\partial \bar{B}_{x}}{\partial z}(a, \bar{t})=0=\frac{\partial \bar{B}_{y}}{\partial z}(a, \bar{t}), \\
-k_{n f} \frac{\partial T}{\partial z}(a, \bar{t})=h\left[T(a, \bar{t})-T_{\infty}\right]
\end{array}\right\},
$$

where $\bar{u}, \bar{v}, \bar{B}_{x}$ and $\bar{B}_{y}, T$ are the nanofluid velocity in $x$ direction, nanofluid velocity in $y$-direction, induced magnetic fields in $x$-direction, induced magnetic field in $y$-direction and temperature of the nanofluid respectively. The quantities $\bar{p}, \bar{t}, T_{\infty}, \varphi, h, \mu_{e}, \omega_{e}, \tau_{e}$ are respectively the nanofluid modified pressure, time, ambient temperature, nanoparticle volume fraction, heat transfer coefficient, magnetic permeability, cyclotron frequency and electron collision time. The quantities subscripted with $(n f)$ are the effective thermophysical quantities of the nanofluid where $\mu_{n f}$ is the dynamic viscosity of the nanofluid, $\rho_{n f}$ is the density of the nanofluid, $v_{n f}$ is the kinematic viscosity of the nanofluid, $\alpha_{n f}$ is the thermal diffusivity of the nanofluid, $\sigma_{n f}$ is the electrical 
conductivity of the nanofluid and $\left(\rho c_{p}\right)_{n f}$ is the heat capacitance of the nanofluid which are given by

$$
\begin{aligned}
& \mu_{n f}=\frac{\mu_{f}}{(1-\phi)^{2.5}}, \quad \rho_{n f}=(1-\phi) \rho_{f}+\phi \rho_{s}, \quad \alpha_{n f}=\frac{k_{n f}}{\left(\rho c_{p}\right)_{n f}}, \quad v_{n f}=\frac{\mu_{n f}}{\rho_{n f}}, \tau_{1}=\frac{\left(\rho c_{p}\right)_{s}}{\left(\rho c_{p}\right)_{f}} \\
& \frac{k_{n f}}{k_{f}}=\frac{\left(k_{s}+2 k_{f}\right)-2 \phi\left(k_{f}-k_{s}\right)}{\left(k_{s}+2 k_{f}\right)+\phi\left(k_{f}-k_{s}\right)}, \quad \frac{\sigma_{n f}}{\sigma_{f}}=1+\frac{3\left(\tau_{3}-1\right) \phi}{\left(\tau_{3}+2\right)-\left(\tau_{3}-1\right) \phi}, \quad \tau_{3}=\frac{\sigma_{s}}{\sigma_{f}}, \quad \tau_{2}=\frac{\rho_{s}}{\rho_{f}}
\end{aligned}
$$

Nanofluid thermal conductivity is represented by $k_{n f}, \rho_{f}$ is the reference density of the fluid fraction, $\rho_{s}$ is the reference density of the solid fraction, $\mu_{f}$ is the dynamic viscosity of the fluid fraction, $k_{f}$ is the thermal conductivity of the fluid fraction, $c_{p}$ is the specific heat at constant pressure, $\sigma_{s}$ is the electrical conductivity of the solid fraction, $\sigma_{f}$ is the electrical conductivity of the fluid fraction and $k_{s}$ is the thermal conductivity of the solid volume fraction. The pressure along $z$-direction is constant; this is clearly evident in Eq. (3). We assume constant pressure gradients along $x$ and $y$ directions. The pressure gradient terms in Eqs. (1) and (2) are modified by considering the boundary conditions at the moving plate given in Eq. (8) as

$$
-\frac{1}{\rho_{n f}} \frac{\partial \bar{p}}{\partial \bar{x}}=0,-\frac{1}{\rho_{n f}} \frac{\partial \bar{p}}{\partial \bar{y}}=2 \omega U .
$$

Substituting these values of pressure gradients in Eqs. (1) and (2) we get

$$
\begin{gathered}
\frac{\partial \bar{u}}{\partial \bar{t}}=2 \omega \bar{v}+v_{n f} \frac{\partial^{2} \bar{u}}{\partial z^{2}}+\frac{B_{0}}{\rho_{n f} \mu_{e}} \frac{\partial \bar{B}_{x}}{\partial z}, \\
\frac{\partial \bar{v}}{\partial \bar{t}}=-2 \omega(\bar{u}-U)+v_{n f} \frac{\partial^{2} \bar{v}}{\partial z^{2}}+\frac{B_{0}}{\rho_{n f} \mu_{e}} \frac{\partial \bar{B}_{y}}{\partial z} .
\end{gathered}
$$

The following non-dimensional variables and parameters are introduced;

$$
\left.\begin{array}{l}
\theta=\frac{T-T_{0}}{T_{\infty}-T_{0}}, \quad u=\frac{\bar{u}}{U}, \quad v=\frac{\bar{v}}{U}, \quad \eta=\frac{z}{a}, \quad t=\frac{\bar{t} v}{a^{2}}, \quad v_{f}=\frac{\mu_{f}}{\rho_{f}}, \quad B i=\frac{h a}{k_{f}} \\
\operatorname{Pr}=\frac{\mu_{f} c_{p f}}{k_{f}}, \quad E c=\frac{U^{2}}{c_{P f}\left(T_{\infty}-T_{0}\right)}, \quad E k=\frac{v_{f}}{\omega a^{2}}, \quad \operatorname{Re}=\frac{U a}{v_{f}}, \quad H a=B_{0} a \sqrt{\frac{\sigma_{f}}{\mu_{f}}} \\
B_{x}=\frac{\bar{B}_{x}}{B_{0}}, \quad B_{y}=\frac{\bar{B}_{y}}{B_{0}}, \quad R_{m}=a \mu_{e} U \sigma_{f}, \quad m=\omega_{e} \tau_{e}
\end{array}\right\}
$$

Substituting Eq. (13) into Eqs. (4)-(6) and (11)-(12) we have;

$$
\begin{aligned}
& \frac{\partial u}{\partial t}=A K v+\frac{\partial^{2} u}{\partial \eta^{2}}+\frac{H a^{2} C}{r R_{m}} \frac{\partial B_{x}}{\partial \eta}, \\
& \frac{\partial v}{\partial t}=-A K(u-1)+\frac{\partial^{2} v}{\partial \eta^{2}}+\frac{H a^{2} C}{r R_{m}} \frac{\partial B_{y}}{\partial \eta}, \\
& \frac{\partial \theta}{\partial t}=\frac{D}{\operatorname{Pr}} \frac{\partial^{2} \theta}{\partial \eta^{2}}+F E c\left[\left(\frac{\partial u}{\partial \eta}\right)^{2}+\left(\frac{\partial v}{\partial \eta}\right)^{2}\right]+\frac{E c H a^{2} C F}{r^{2} R_{m}{ }^{2}}\left[\left(\frac{\partial B_{x}}{\partial \eta}\right)^{2}+\left(\frac{\partial B_{y}}{\partial \eta}\right)^{2}\right],
\end{aligned}
$$

with initial and boundary conditions

$$
\begin{gathered}
u(\eta, 0)=0=v(\eta, 0), \quad \theta(\eta, 0)=0, \quad B_{x}(0, \eta)=0=B_{y}(0, \eta), \\
u(0, t)=0=v(0, t), \quad B_{x}(0, t)=0=B_{y}(0, t), \quad \theta(0, t)=0 \\
\left.u(1, t)=1, \quad v(1, t)=0, \quad \frac{\partial B_{x}}{\partial \eta}(1, t)=0=\frac{\partial B_{y}}{\partial \eta}(1, t), \quad-\frac{\partial \theta}{\partial \eta}(1, t)=\frac{B i}{n}[\theta(1, t)-1]\right\},
\end{gathered}
$$

where $P r, B i, E c, K, H a, R e, R_{m}$ and $m$ are respectively the Prandtl number, Biot number Eckert number, rotation parameter (reciprocal of Ekman number $E k$ ), Hartmann number, flow Reynolds number, magnetic Reynolds number and Hall current 
parameter respectively. The values of $A, C, D, F, r$ and $n$ which depend on $\varphi$ are defined as

$$
\left.\begin{array}{c}
A=2(1-\phi)^{2.5}\left[1-\phi+\phi \tau_{2}\right], \quad C=(1-\phi)^{2.5}\left[1+\frac{3\left(\tau_{3}-1\right) \phi}{\left(\tau_{3}+2\right)-\left(\tau_{3}-1\right) \phi}\right] \\
D=\frac{(1-\phi)^{2.5}\left(1-\phi+\phi \tau_{2}\right)\left[k_{s}+2 k_{f}-2 \phi\left(k_{f}-k_{s}\right)\right]}{\left(1-\phi+\phi \tau_{1}\right)\left[k_{s}+2 k_{f}+\phi\left(k_{f}-k_{s}\right)\right]}, \quad F=\frac{1-\phi+\phi \tau_{2}}{1-\phi+\phi \tau_{1}} \\
n=\frac{k_{s}+2 k_{f}-2 \phi\left(k_{f}-k_{s}\right)}{k_{s}+2 k_{f}+\phi\left(k_{f}-k_{s}\right)}, \quad r=1+\frac{3\left(\tau_{3}-1\right) \phi}{\left(\tau_{3}+2\right)-\left(\tau_{3}-1\right) \phi}
\end{array}\right\} .
$$

Skin friction $C_{f}$ and local Nusselt number $N u$ are the quantities of practical interest in this study. These are defined as;

$$
\begin{gathered}
C_{f x, y}=\frac{\tau_{x, y}}{\rho_{f} U^{2}}, \quad N u=\frac{a q_{w}}{k_{f}\left(T_{\infty}-T_{0}\right)}, \\
\tau_{x}=\left.\mu_{n f} \frac{\partial \bar{u}}{\partial z}\right|_{z=0, a}, \quad \tau_{y}=\left.\mu_{n f} \frac{\partial \bar{v}}{\partial z}\right|_{z=0, a}, \quad q_{w}=-\left.k_{n f} \frac{\partial T}{\partial z}\right|_{z=a} .
\end{gathered}
$$
given by respectively and $q_{w}$ is the heat flux at the upper moving plate

Substituting Eq (23) into (22) and introducing dimensionless variables we have;

$$
\operatorname{Re} C_{f x}=\left.\frac{1}{(1-\phi)^{2.5}} \frac{\partial u}{\partial \eta}\right|_{\eta=0,1}, \operatorname{Re}_{f} C_{f y}=\left.\frac{1}{(1-\phi)^{2.5}} \frac{\partial v}{\partial \eta}\right|_{\eta=0,1}, N u=-\left.n \frac{\partial \theta}{\partial \eta}\right|_{\eta=1} .
$$

Table 1. Thermophysical Properties of Materials [12].

\begin{tabular}{lllll}
\hline Materials & $\boldsymbol{\rho}\left(\mathrm{kg} / \mathbf{m}^{3}\right)$ & $\boldsymbol{c}_{p}(\mathbf{J} / \mathbf{k g ~ K})$ & $\boldsymbol{k}(\mathbf{W} / \mathbf{m K})$ & $\sigma(\mathrm{S} / \mathbf{m})$ \\
\hline Pure water & 997.1 & 4179 & 0.613 & $5.5 \times 10^{-6}$ \\
Alumina $\left(\mathrm{Al}_{2} \mathrm{O}_{3}\right)$ & 3970 & 765 & 40 & $35 \times 10^{6}$ \\
Titania $\left(\mathrm{TiO}_{2}\right)$ & 4250 & 686.2 & 8.9538 & $2.6 \times 10^{6}$ \\
Copper $(\mathrm{Cu})$ & 8933 & 385 & 401 & $59.6 \times 10^{6}$ \\
\hline
\end{tabular}

\section{Numerical Procedures}

\subsection{Finite Element (Gelarkin Approximation)}

In this section, the governing non-linear system of PDEs (14)-(18) are solved numerically using finite element technique. The spatial variable is discretized based on the Gelarkin approximation and the time variable is discretized using Crank-Nicolson scheme. We first consider the linear Eqs. (14)-(17) which are solvable without considering Eq. (18). Thereafter, Eq. (18) is solved separately using the results obtained after solving Eqs. (14)-(17). The following definitions are worth introduced:

$$
f(\eta, t)=F E c\left[\left(\frac{\partial u}{\partial \eta}\right)^{2}+\left(\frac{\partial v}{\partial \eta}\right)^{2}\right]+\frac{E c H a^{2} C F}{r^{2} R_{m}^{2}}\left[\left(\frac{\partial B_{x}}{\partial \eta}\right)^{2}+\left(\frac{\partial B_{y}}{\partial \eta}\right)^{2}\right]
$$

$$
\begin{aligned}
& \frac{\partial(.)}{\partial t}=(.), \frac{\partial(.)}{\partial \eta}=(.)^{\prime}, f\left(\eta, t_{j}\right)=f^{j}, \quad f\left(\eta_{i}, t\right)=f_{i}, \\
& (f, g)=\int_{\Omega} f g d \Omega \\
& \left(\dot{u}, w_{1}\right)=k_{1}\left(v, w_{1}\right)-\left(u^{\prime}, w_{1}^{\prime}\right)+k_{2}\left(B_{x}^{\prime}, w_{1}\right) \\
& \left(\dot{v}, w_{2}\right)=k_{1}\left(u, w_{2}\right)-\left(v^{\prime}, w_{2}^{\prime}\right)+k_{2}\left(B_{y}^{\prime}, w_{2}\right)+k_{1}\left(1, w_{2}\right) \\
& \left(\dot{B}_{x}, w_{3}\right)=k_{3}\left(u^{\prime}, w_{3}\right)-k_{4}\left(B_{x}^{\prime}, w_{3}^{\prime}\right)-k_{5}\left(B_{y}^{\prime}, w_{3}^{\prime}\right) \\
& \left(\dot{B}_{y}, w_{4}\right)=k_{3}\left(v^{\prime}, w_{3}\right)-k_{4}\left(B_{y}^{\prime}, w_{4}^{\prime}\right)-k_{5}\left(B_{x}^{\prime}, w_{4}^{\prime}\right) \\
& \left.\left(\dot{\theta}, w_{5}\right)=-k_{6}\left(\theta^{\prime}, w_{5}^{\prime}\right)+\left(f(\eta, t), w_{5}\right)+k_{7}\left[w_{5}(1, t)-\theta(1, t) w_{5}(1, t)\right]\right)
\end{aligned}
$$

Also, for compactness we let $k_{1}=A K, k_{2}=H a^{2} C / r R_{m}$, $k_{3}=A \operatorname{Re}, k_{4}=A \operatorname{Re} / r R_{m}, k_{5}=m A \operatorname{Re} / r R_{m}, k_{6}=D / \operatorname{Pr}$ and $k_{7}=D B i / n \operatorname{Pr}$. The variational formulation of the system of Eqs. (14)-(18) reads: find $u, v, B_{x}, B_{y}, \theta \in H^{1}[0,1]$ such that 
$\forall w_{1}, w_{2}, w_{3}, w_{4}, w_{5} \in H^{1}[0,1]$ chosen such that $w_{1}(0, t)=0, w_{2}(0, t)=0, w_{3}(0, t)=0, w_{4}(0, t)=0, w_{5}(0, t)=0$. The finite element approximation to the variational Eqs. (28) is obtained by replacing $H^{1}$ the by subspace $V_{h} \subset H^{1}$ of all continuous piecewise linear functions. The resulting approximations take the form: find: $u^{h}, v^{h}, B_{x}^{h}, B_{y}^{h}, \theta^{h} \in H^{1}[0,1]$ such that

$$
\left.\begin{array}{l}
\left(\dot{u}^{h}, w_{1}\right)=k_{1}\left(v^{h}, w_{1}\right)-\left(u^{h^{\prime}}, w_{1}^{\prime}\right)+k_{2}\left(B_{x}^{h^{\prime}}, w_{1}\right) \\
\left(\dot{v}^{h}, w_{2}\right)=k_{1}\left(u^{h}, w_{2}\right)-\left(v^{h^{\prime}}, w_{2}^{\prime}\right)+k_{2}\left(B_{y}^{h^{\prime}}, w_{2}\right)+k_{1}\left(1, w_{2}\right) \\
\left(\dot{B}_{x}^{h}, w_{3}\right)=k_{3}\left(u^{\prime}, w_{3}\right)-k_{4}\left(B_{x}^{h^{\prime}}, w_{3}^{\prime}\right)-k_{5}\left(B_{y}^{h^{\prime}}, w_{3}^{\prime}\right) \\
\left(\dot{B}_{y}^{h}, w_{4}\right)=k_{3}\left(v^{h^{\prime}}, w_{3}\right)-k_{4}\left(B_{y}^{h^{\prime}}, w_{4}^{\prime}\right)-k_{5}\left(B_{x}^{h^{\prime}}, w_{4}^{\prime}\right) \\
\left(\dot{\theta}^{h}, w_{5}\right)=-k_{6}\left(\theta^{h^{\prime}}, w_{5}^{\prime}\right)+\left(f(\eta, t), w_{5}\right)+k_{7}\left[w_{5}(1, t)-\theta(1, t) w_{5}(1, t)\right]
\end{array}\right\},
$$

$\forall w_{1}, w_{2}, w_{3}, w_{4}, w_{5} \in V_{h}$.

In that respect, if $N-1$ of equal length $l$ are considered, there exist $N$ equally spaced nodes, and each of the functions $u^{h}, v^{h}, B_{x}^{h}, B_{y}^{h}, \theta^{h}$ and $w_{\{k=1, \ldots, 5\}}$ can be expressed in the form of

$$
\zeta(\eta, t)=\sum_{i=1}^{N} \zeta_{i}(t) \varphi_{i}(\eta)
$$

where $\zeta_{i}(t)$ are time dependent coefficients to be

$$
\left.\begin{array}{l}
a_{1}^{e}=\frac{1}{l}\left(\begin{array}{rr}
1 & -1 \\
-1 & 1
\end{array}\right), a_{2}^{e}=\frac{l}{6}\left(\begin{array}{cc}
2 & 1 \\
1 & 2
\end{array}\right), a_{3}^{e}=\frac{1}{2}\left(\begin{array}{ll}
-1 & 1 \\
-1 & 1
\end{array}\right), b_{1}^{e}=\frac{l}{2}\left(\begin{array}{l}
1 \\
1
\end{array}\right) \\
a_{4}^{e}=k_{7}\left(\begin{array}{cc}
\varphi_{i}(1) \varphi_{i}(1) & \varphi_{i}(1) \varphi_{i+1}(1) \\
\varphi_{i}(1) \varphi_{i+1}(1) & \varphi_{i+1}(1) \varphi_{i+1}(1)
\end{array}\right), b_{2}^{e}=k_{7}\left(\begin{array}{c}
\varphi_{i}(1) \\
\varphi_{i+1}(1)
\end{array}\right), b_{3}^{e}=\frac{l}{6}\left(\begin{array}{c}
2 f_{i}+f_{i+1} \\
f_{i}+2 f_{i+1}
\end{array}\right)
\end{array}\right\} .
$$

The first four equations of the system (29) in matrix form is given as:

$$
\begin{gathered}
M_{1} \dot{\xi}=M_{2} \xi+\xi_{c}, \quad\left(\begin{array}{cccc}
a_{2} & 0 & 0 & 0 \\
0 & a_{2} & 0 & 0 \\
0 & 0 & a_{2} & 0 \\
0 & 0 & 0 & a_{2}
\end{array}\right), M_{2}=\left(\begin{array}{cccc}
-a_{1} & k_{1} a_{2} & k_{2} a_{3} & 0 \\
-k_{1} a_{2} & -a_{1} & 0 & k_{2} a_{3} \\
k_{3} a_{3} & 0 & k_{4} a_{1} & -k_{5} a_{1} \\
0 & k_{3} a_{3} & k_{5} a_{1} & k_{4} a_{1}
\end{array}\right), \xi=\left(\begin{array}{c}
\tilde{u} \\
\tilde{v} \\
\tilde{B}_{x} \\
\tilde{B}_{y}
\end{array}\right), \xi_{c}=\left(\begin{array}{c}
0 \\
k_{1} b_{1} \\
0 \\
0
\end{array}\right)
\end{gathered}
$$

$a_{1}, a_{2}, a_{3}$ and $b_{1}$ are global matrices associated with the element matrices $a_{1}^{e}, a_{2}^{e}, a_{3}^{e}$ and $b_{1}^{e}$ respectively; $\tilde{u}, \tilde{v}, \tilde{B}_{x}$ and $\tilde{B}_{y}$ are $N \times 1$ matrices containing the nodal values of $u$, $v, B_{x}$ and $B_{y}$ in the corresponding order.

Applying the famous Crank-Nicholson scheme to Eq. (33), we have:

$$
\left(M_{1}-\alpha M_{2}\right) \xi^{j+1}=\left(M_{1}+\alpha M_{2}\right) \xi^{j}+2 \alpha \xi_{c},
$$

where $\alpha=\Delta t / 2$. The matrices $M_{1}+\alpha M_{2}=B_{1}$, $M_{1}-\alpha M_{2}=B_{2}$ and $\xi_{c}$ are modified to incorporate the boundary conditions resulting into the equation where $M_{1}, M_{2}, \xi$ and $\xi_{c}$ are block matrices given by:

$$
B_{1} \xi^{j+1}=B_{2} \xi^{j}+2 \alpha \xi_{c}+\xi_{B_{2}}-\xi_{B_{1}},
$$

where $\xi_{B_{1}}$ and $\xi_{B_{2}}$ are the $N^{\text {th }}$ columns of matrices $B_{1}$ and $B_{2}$ respectively. The last equation of the system (29) is solved by similar procedures using the results obtained from Eq. (36). The approximate solution is given in matrix form as:

$$
a_{2} \dot{\tilde{\theta}}=-\left(k_{6} a_{1}+a_{4}\right) \tilde{\theta}+b_{2}+b_{3},
$$

where $a_{4}, b_{2}$ and $b_{3}$ are the global matrices associated with the element matrices $a_{4}^{e}, b_{2}^{e}, b_{3}^{e}$. 
$\tilde{\theta}$ is an $N \times 1$ matrix containing the nodal values of function $\theta$. The final equation after incorporating the boundary conditions is:

$$
C_{1} \tilde{\theta}^{j+1}=C_{2} \tilde{\theta}^{j}+\alpha\left(2 b_{2}+b_{3}^{j}+b_{3}^{j+1}\right),
$$

\subsection{Method of Lines}

Let $u_{i}(t), v_{i}(t), B_{x i}(t), B_{y i}(t)$ and $\theta_{i}(t)$ be the approximation of $u\left(\eta_{i}, t\right), v\left(\eta_{i}, t\right), B_{x}\left(\eta_{i}, t\right), B_{y}\left(\eta_{i}, t\right)$ and $\theta\left(\eta_{i}, t\right)$ respectively. For equations compactness, the following definitions are introduced:

where $C_{1}=a_{2}+\alpha\left(k_{6} a_{1}+a_{4}\right)$ and $C_{2}=a_{2}-\alpha\left(k_{6} a_{1}+a_{4}\right)$.

$$
g_{i}(x)=x_{i}(t), \quad g_{i}^{\prime}(x)=\frac{x_{i+1}(t)-x_{i-1}(t)}{2 \Delta \eta}, \quad g_{i}^{\prime \prime}(x)=\frac{x_{i-1}(t)-2 x_{i}(t)+x_{i+1}(t)}{\Delta \eta^{2}},
$$

Using Eq. (39) the semi-discretization scheme for the problem is given as

$$
\begin{aligned}
& \frac{d g_{i}\left(B_{x}\right)}{d t}=k_{3} g_{i}^{\prime}(u)+k_{4} g_{i}^{\prime \prime}\left(B_{x}\right)+k_{5} g_{i}^{\prime \prime}\left(B_{y}\right), \\
& \frac{d g_{i}\left(B_{y}\right)}{d t}=k_{3} g_{i}^{\prime}(v)+k_{4} g_{i}^{\prime \prime}\left(B_{y}\right)-k_{5} g_{i}^{\prime \prime}\left(B_{x}\right),
\end{aligned}
$$

$$
\begin{gathered}
\frac{d g_{i}(u)}{d t}=k_{1} g_{i}(v)+g_{i}^{\prime \prime}(u)+k_{2} g_{i}^{\prime}\left(B_{x}\right), \\
\frac{d g_{i}(v)}{d t}=-k_{1}\left[g_{i}(u)-1\right]+g_{i}^{\prime \prime}(v)+k_{2} g_{i}^{\prime}\left(B_{y}\right),
\end{gathered}
$$

$$
\frac{d g_{i}(\theta)}{d t}=k_{6} g_{i}^{\prime \prime}(\theta)+k_{7}\left\{\left[g_{i}^{\prime}(u)\right]^{2}+\left[g_{i}^{\prime}(v)\right]^{2}\right\}+k_{8}\left\{\left[g_{i}^{\prime}\left(B_{x}\right)\right]^{2}+\left[g_{i}^{\prime}\left(B_{y}\right)\right]^{2}\right\},
$$

with initial conditions

$$
u_{i}(0)=0=v_{i}(0), B_{x i}(0)=0=B_{y i}(0), \quad \theta_{i}(0)=0 \text { for } 1 \leq i \leq N .
$$

The equations corresponding to the first and last grid points are modified to incorporate the boundary conditions as follows

$$
\begin{aligned}
& u_{0}=0, \quad v_{0}=0, B_{x 0}=0, B_{y 0}=0, \theta_{0}=0, \\
& \left.u_{\mathrm{N}+1}=1, \quad v_{N+1}=0, B_{x(N+1)}=B_{x N}(t), B_{y(N+1)}=B_{y N}(t), \theta_{N+1}=\frac{n \theta_{N}(t)+\Delta \eta B i}{n+\Delta \eta B i}\right\} .
\end{aligned}
$$

Similarly, the space discretization for skin friction and Nusselt number given in Eq. (24) are performed based on backward and forward finite difference approximations and the results are evaluated at $\eta=0$ and $\eta=1$ as follows:

$$
\left.\begin{array}{l}
\operatorname{Re}_{f} C_{f x 0}=\frac{1}{(1-\phi)^{2.5}}\left(\frac{u_{1}(t)-u_{0}}{\Delta \eta}\right), \quad \operatorname{Re}_{f} C_{f y 0}=\frac{1}{(1-\phi)^{2.5}}\left(\frac{v_{1}(t)-v_{0}}{\Delta \eta}\right) \\
\operatorname{Re}_{f} C_{f x 1}=\frac{1}{(1-\phi)^{2.5}}\left(\frac{u_{N+1}-u_{N}(t)}{\Delta \eta}\right), \quad \operatorname{Re}_{f} C_{f y 1}=\frac{1}{(1-\phi)^{2.5}}\left(\frac{v_{N+1}-v_{N}(t)}{\Delta \eta}\right) \\
N u=\frac{n B i\left[\theta_{N}(t)-1\right]}{n+B i \Delta \eta}
\end{array}\right\},
$$

where $u_{0}=0, v_{0}=0, u_{N+1}=1, v_{N+1}=0$ are the boundary conditions at the lower and upper plates. Equations (40)-(44) is a system of first order ordinary differential equations with known initial conditions. This is be solved iteratively using Runge-Kutta Fehlberg integration technique [20] implemented using ode15s MATLAB's subroutine. The skinfriction coefficient and the Nusselt number given in Eq. (46) are obtained and their numerical values are presented graphically.

\section{Results and Discussion}

We analyze the results by considering three types of nanoparticles, namely; copper $\mathrm{Cu}, \mathrm{Al}_{2} \mathrm{O}_{3}$ and $\mathrm{TiO}_{2}$ with water as base a fluid. Unless otherwise stated, the $\mathrm{Cu}$-water nanofluid is used and the following parameter values are employed: $\phi=0.15, \operatorname{Pr}=6.2, E c=1, M^{2}=10, E k=1 / 3$, $R m=2, \operatorname{Re}=1, m=1$ and $B i=1$. 


\subsection{Transient Analysis}

Figure 2. highlights the dynamics for velocity, induced magnetic fields and heat transfer profiles. The velocity profiles are given in Fig. 2(a) where the primary velocity is observed to rise with some oscillations from its zero initial value and attained a steady state shortly after the commencement of the flow. It also increases gradually from zero at the stationary plate to maximum velocity at the moving plate. The secondary velocity on the other hand is observed to have maximum value near the stationary plate. As seen in Fig. 2(b) and Fig. 2(c), the induced magnetic fields are observed to have similar trend and attained their
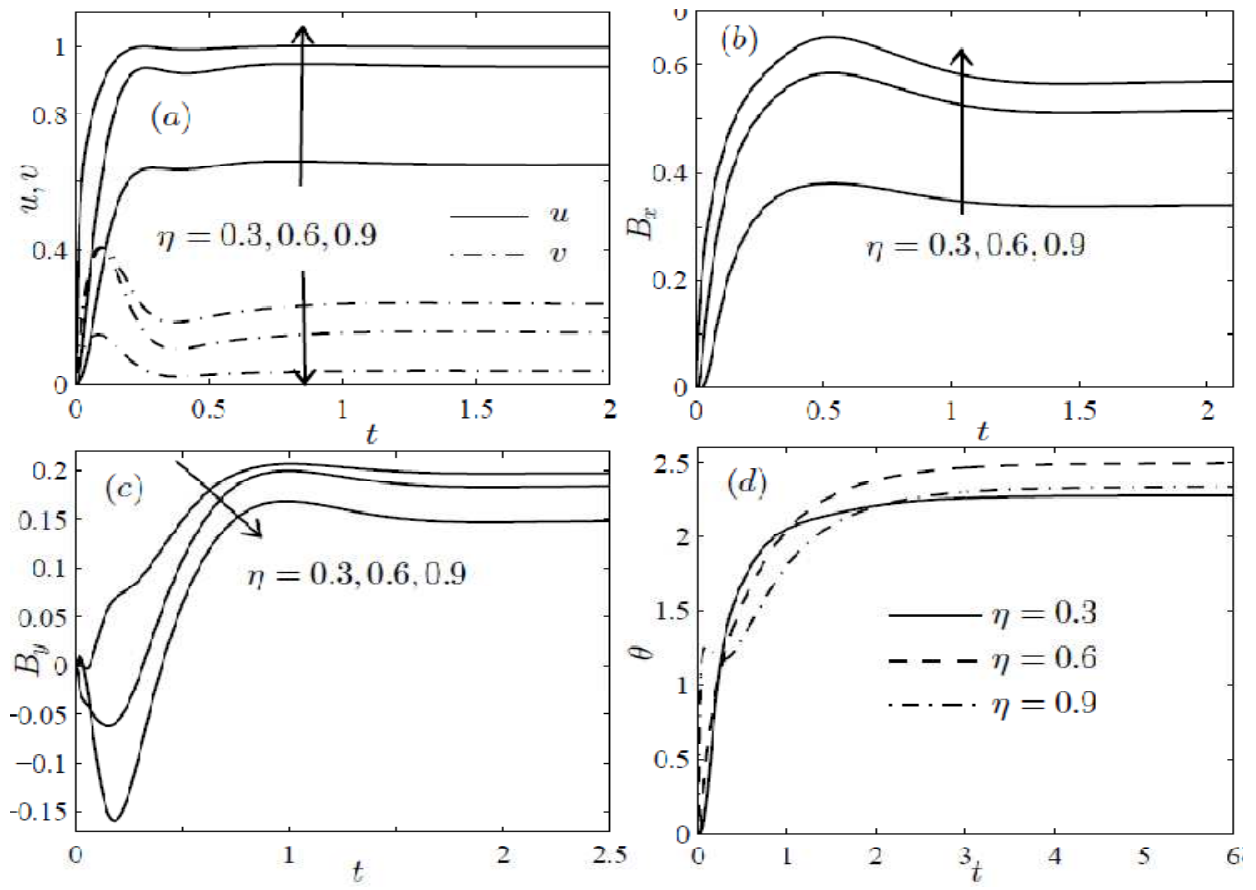

Fig. 2. Unsteady behaviours with increasing $\eta$.
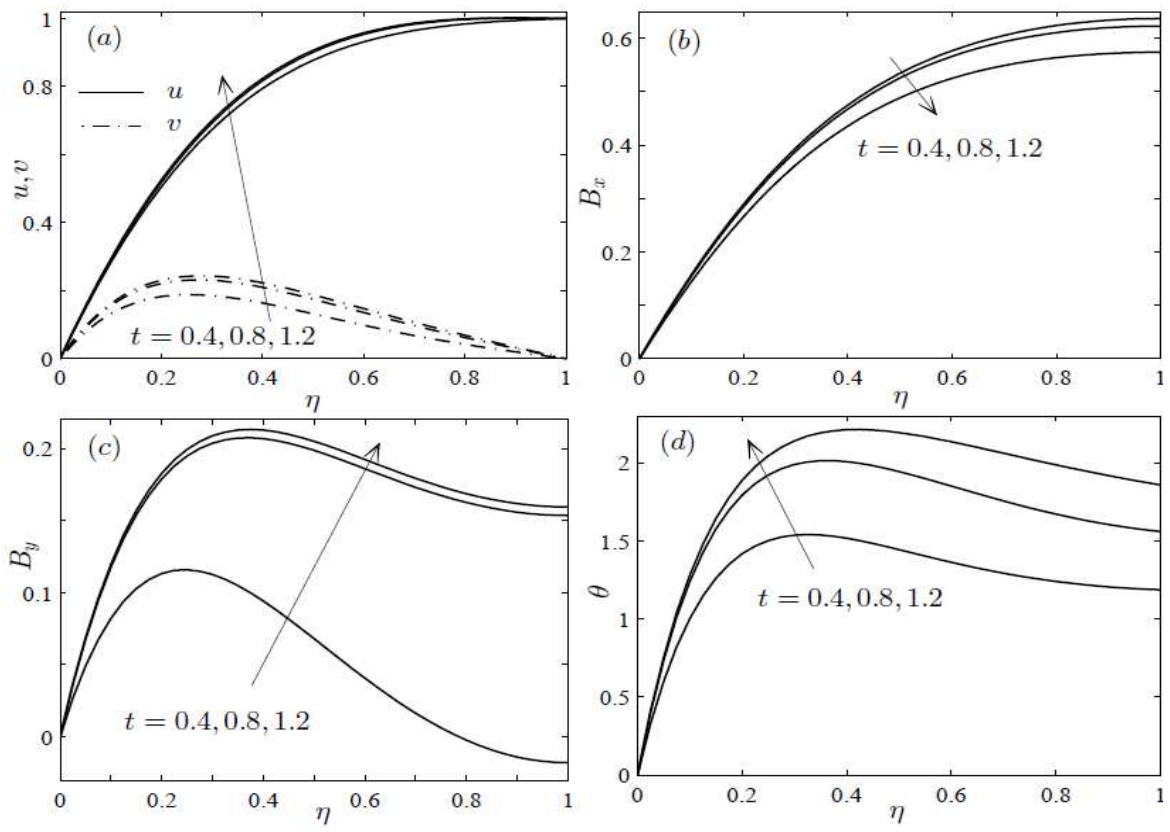

Fig. 3. Unsteady behaviours with increasing time. steady state at about $t=2$. The primary induced magnetic field is increasing towards the moving plate and the secondary induced magnetic field is decreasing toward the moving plate. Evolution of temperature profiles is relatively slower and attained steady state profiles later at about $t=6$. The fluid temperature is expectedly higher near the centre of the channel as the temperature at the lower plate is fixed at zero and the upper plate loses heat by convection. The detailed accounts on the transient behaviours of velocity, induced magnetic fields and temperature profiles with increasing time are given in Fig. 3.

. 


\subsection{Effect of Various Types Nanoparticles on Flow Quantities Profiles}

Figure 4. illustrates the effects of various types of nanoparticles on the flow quantities under consideration. The $\mathrm{Cu}$-water nanofluid moves faster in all regions of the channel compared to both $\mathrm{Al}_{2} \mathrm{O}_{3}$-water and $\mathrm{SiO}_{2}$-water nanofluids (see Fig. 4(a)). Induced magnetic fields are depicted in Figs. $4(b)$ and $4(c)$ where $\mathrm{Al}_{2} \mathrm{O}_{3}$-water and $\mathrm{SiO}_{2}$-water produced
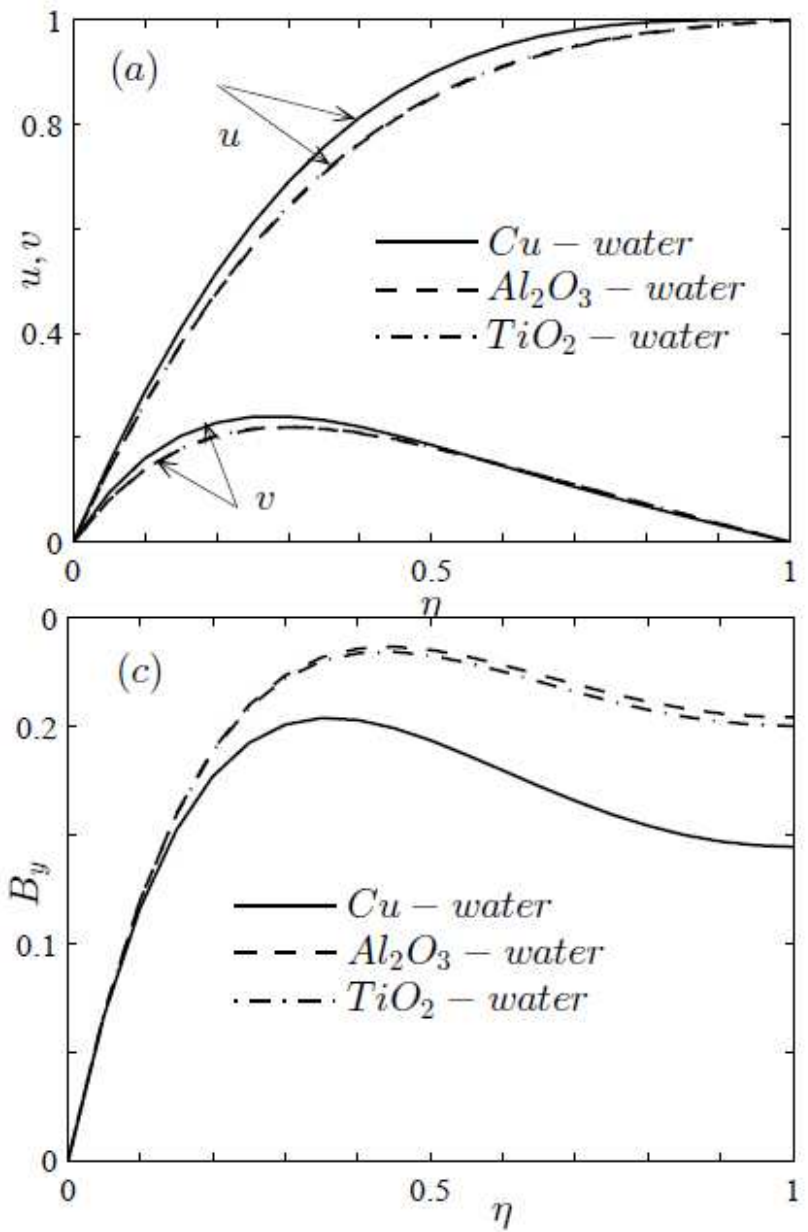

higher and similar levels of induced magnetic fields in both primary and secondary directions. The temperature profiles are depicted in Fig. $4(d)$ where $\mathrm{Cu}$-water nanofluid expectedly demonstrated higher fluid temperature near the lower plate where the temperature is fixed and lower temperature near the upper moving plate where the convective cooling is taking place. $\mathrm{TiO}_{2}$ is observed to have least heat transfer characteristics.
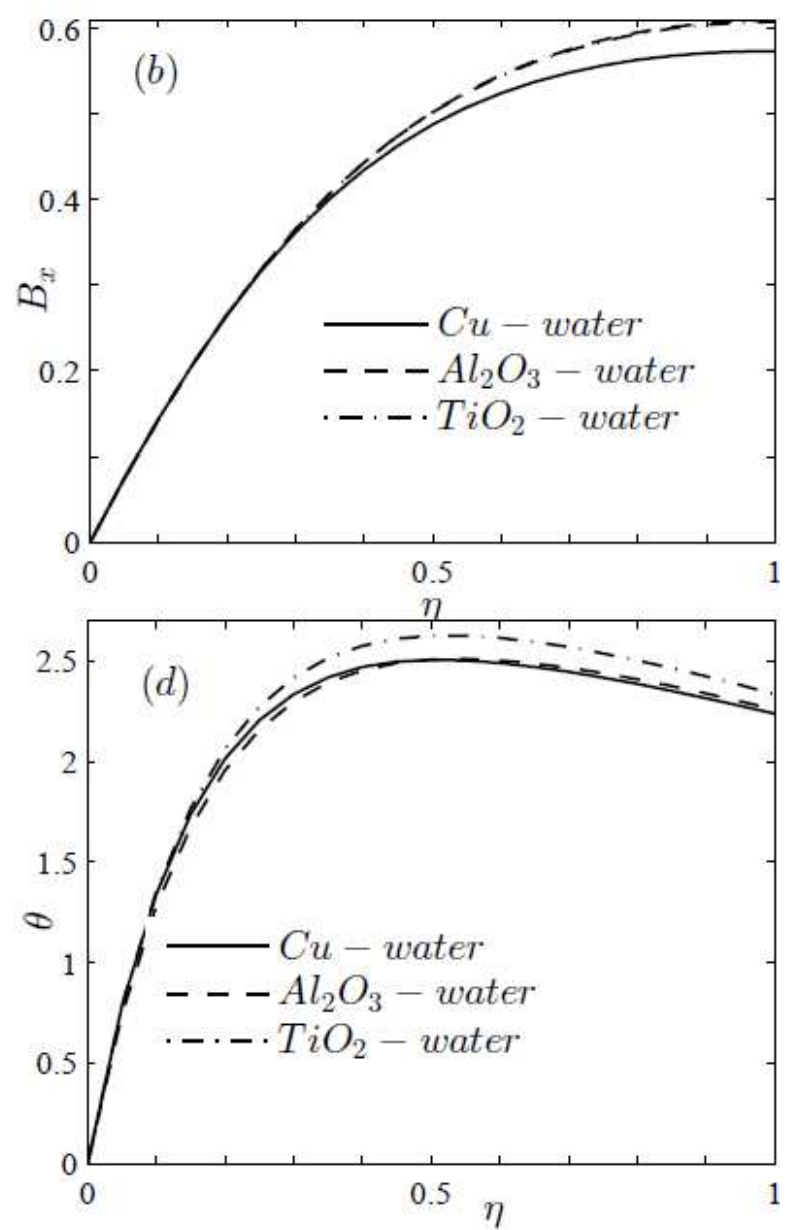

Fig. 4. Flow quantities profiles for $\mathrm{Cu}$-water, $\mathrm{Al}_{2} \mathrm{O}_{3}$ and $\mathrm{TiO}_{2}$ nanofluids.

\subsection{Effect of Various Parameter on Flow Quantities Profiles}

The effect of Hall current on the flow quantities is illustrated in Fig. 5. The primary velocity and primary induced magnetic field profiles are observed to decrease when the Hall current parameter is raised (Figs. 5(a) and $5(b)$ ). Opposite behaviour occurs for the secondary velocity and secondary induced magnetic field profiles (see Figs 5(a) and 5(c)). The reduced secondary velocity and secondary induced magnetic field due to increase in Hall current parameter effectively lower the fluid temperature as can be seen in Fig. $5(d)$.

The effect of magnetic field parameter $(\mathrm{Ha})$ is illustrated in
Fig. 6 where $\mathrm{Ha}$ tends to influence the growth of primary velocity and temperature profiles. The rise in temperature is due to the build up of resistive Lorentz force within the nanofluid. On the other hand, the secondary velocity, primary and secondary induced magnetic fields (Figs. 6(a), 6(b) and 6(c)) are negatively affected when $\mathrm{Ha}$ is increased.

Figure 7 illustrates the effect of rotation parameter $(1 / E k)$ where the rate of rotation boosts the growth of primary velocity and temperature profiles, whereas, the primary induced magnetic fields, secondary induced magnetic field and secondary velocity profiles are observed to decrease when the rotation parameter is increased. 

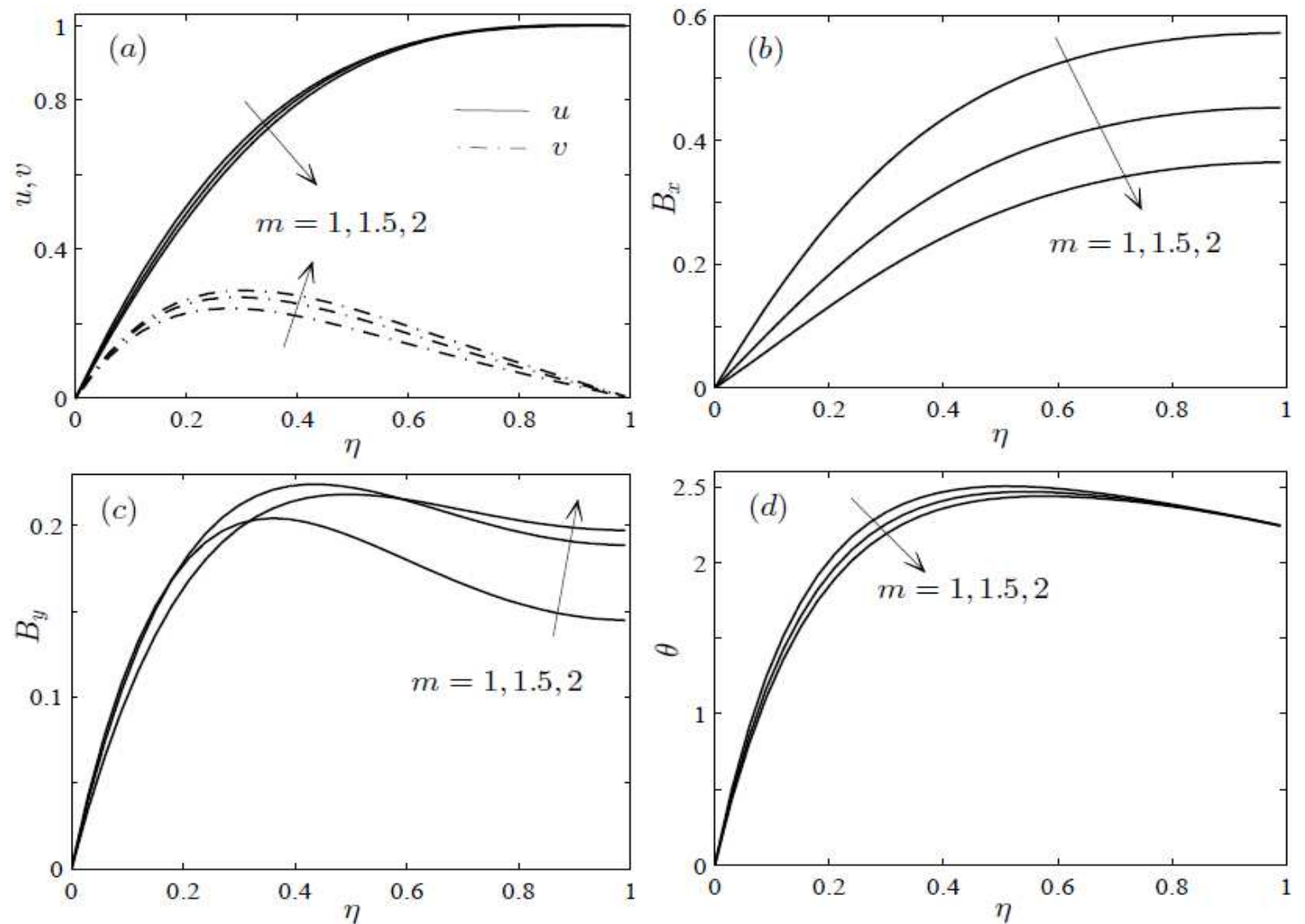

Fig. 5. Effect of Hall current on velocity, magnetic field and temperature profiles.
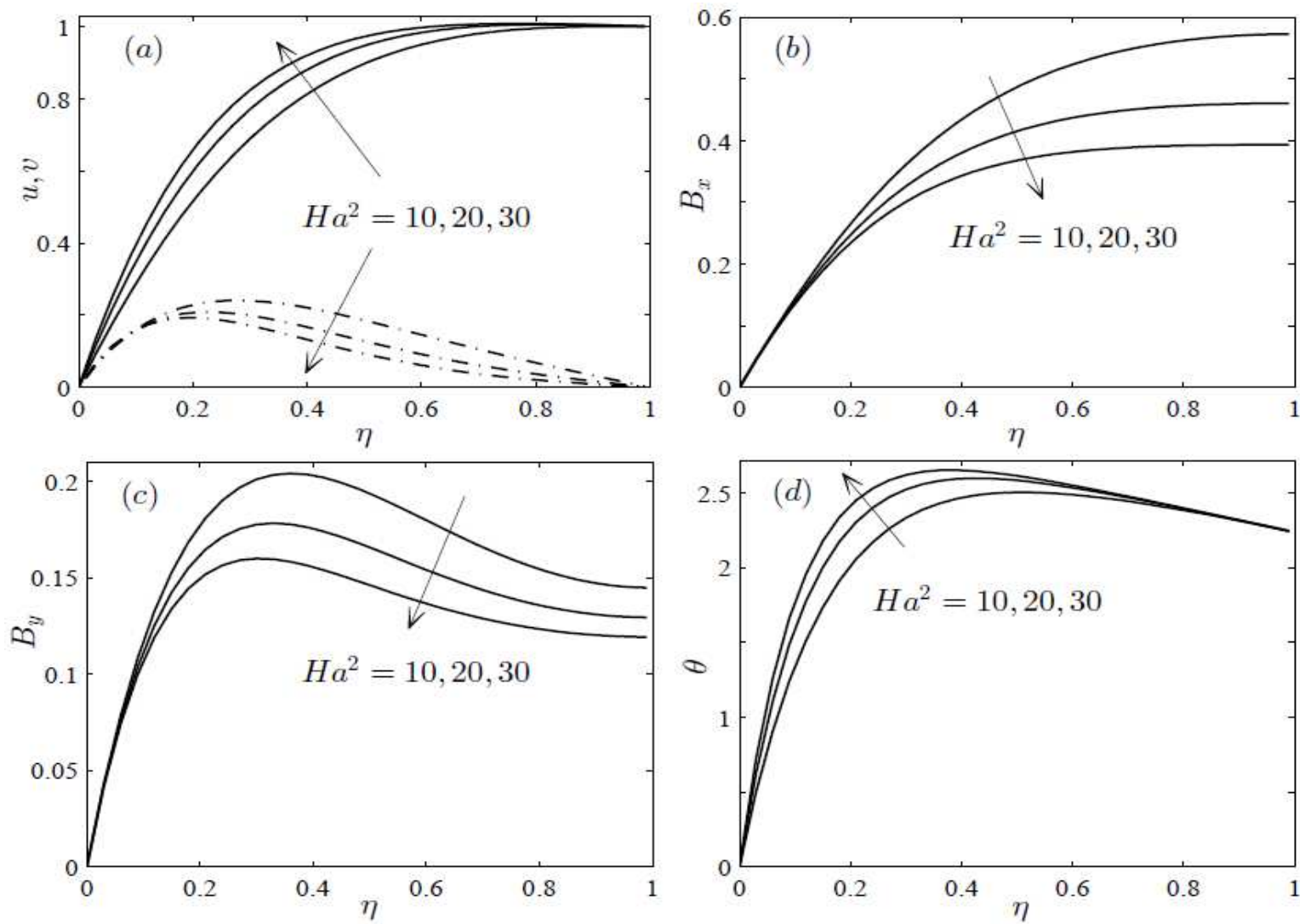

Fig. 6. Effect of magnetic field on velocity, magnetic field and temperature profiles. 

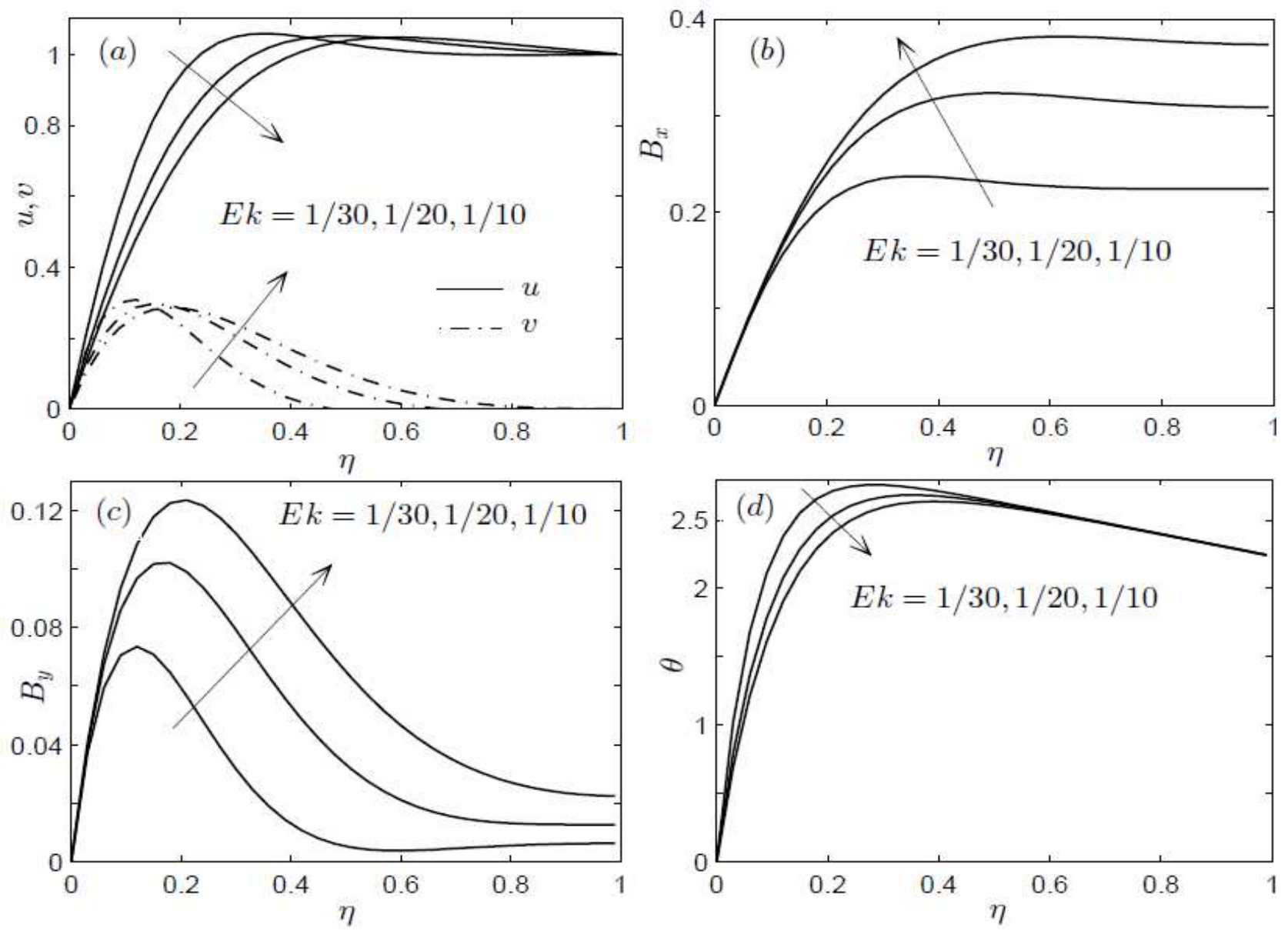

Fig. 7. Effect of rotation on velocity, magnetic field and temperature profiles.

The effect of nanoparticle volume fraction $(\varphi)$ is depicted in Fig. 8 where velocity profiles (Fig. 8(a)) demonstrate no pronounced effect when $\varphi$ is changed. Increased amount of nanoparticle volume fraction in flow enhances the conductivity of nanofluid which in turn causes the growth of induced magnetic fields and temperature profiles in the flow system. The Biot number $(B i)$ controls the convective heat transfer at the upper plate. Figure $9(a)$ presents the effect of Biot number on the temperature profile. It is worth noting that, when $\mathrm{Bi}$ is increased the heat exchange with the ambient surrounding is also increases which result in the temperature drop in the system. Moreover, the increase in Eckert number $(\mathrm{Ec})$, as expected, causes the rise in temperature in the channel (see Fig. 9(b)).

\subsection{Skin Friction and Nusselt Number Profiles}

Figure 10 depicts the skin behaviours of skin friction at the lower plate surface when different parameters and nanoparticles are changed. The time evolution of skin friction at the lower fixed plate for both primary and secondary flow directions is given in Fig. 10(a). After some brief oscillations, the skin friction becomes much more pronounced in the primary flow direction as compared to that of secondary flow direction. At steady state, both the primary and secondary skin friction are observed to increase with rotation parameter $(1 / E k)$ with $\mathrm{Cu}$-water nanofluid demonstrating the highest skin friction coefficient (Fig. 10(b)). Hall current parameter is observed to influence the secondary skin friction but diminishes the primary flow skin friction. Also, as expected, the more nanoparticle volume fraction is introduced in the flow system, the more skin friction is experienced. This is because the fluid becomes more viscous and eventually causes the increased shear stress along the wall surface. Similar effect is observed when magnetic field parameter is changed. Meanwhile, effects of various nanofluids and thermophysical parameters on heat transfer rate $(\mathrm{Nu})$ are clearly presented in Fig. 11.

To validate the accuracy of the numerical results obtained by Galerkin approximation coupled with Crank-Nicholson scheme, another numerical method (method of lines) was used and the results were compared. The results given in Fig. 12 are in perfect agreement with each other and they are presented in Fig. 12. 

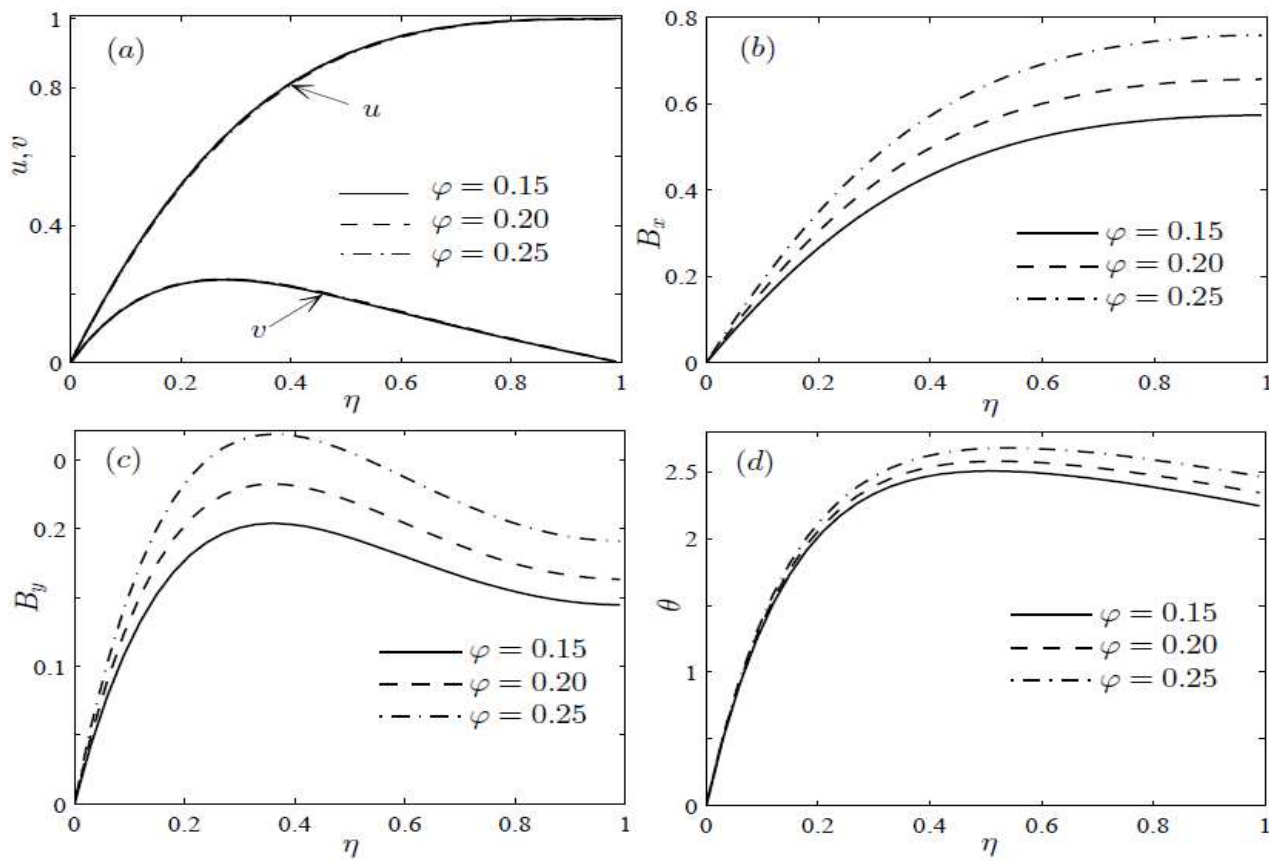

Fig. 8. Effect of nanoparticle volume fraction on the flow quantities profiles.
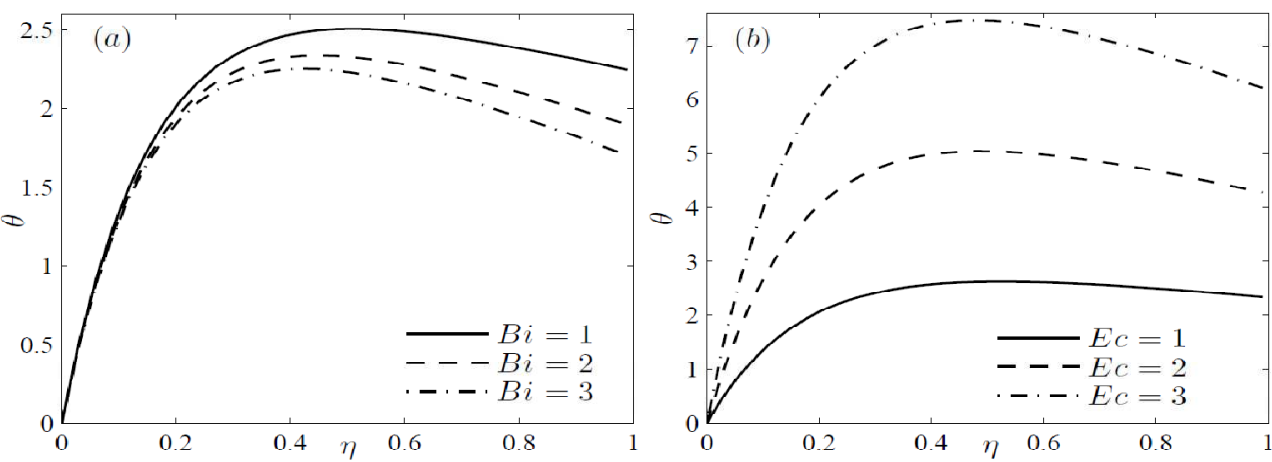

Fig. 9. Effect Bi and Ec on velocity, magnetic field and temperature profiles.
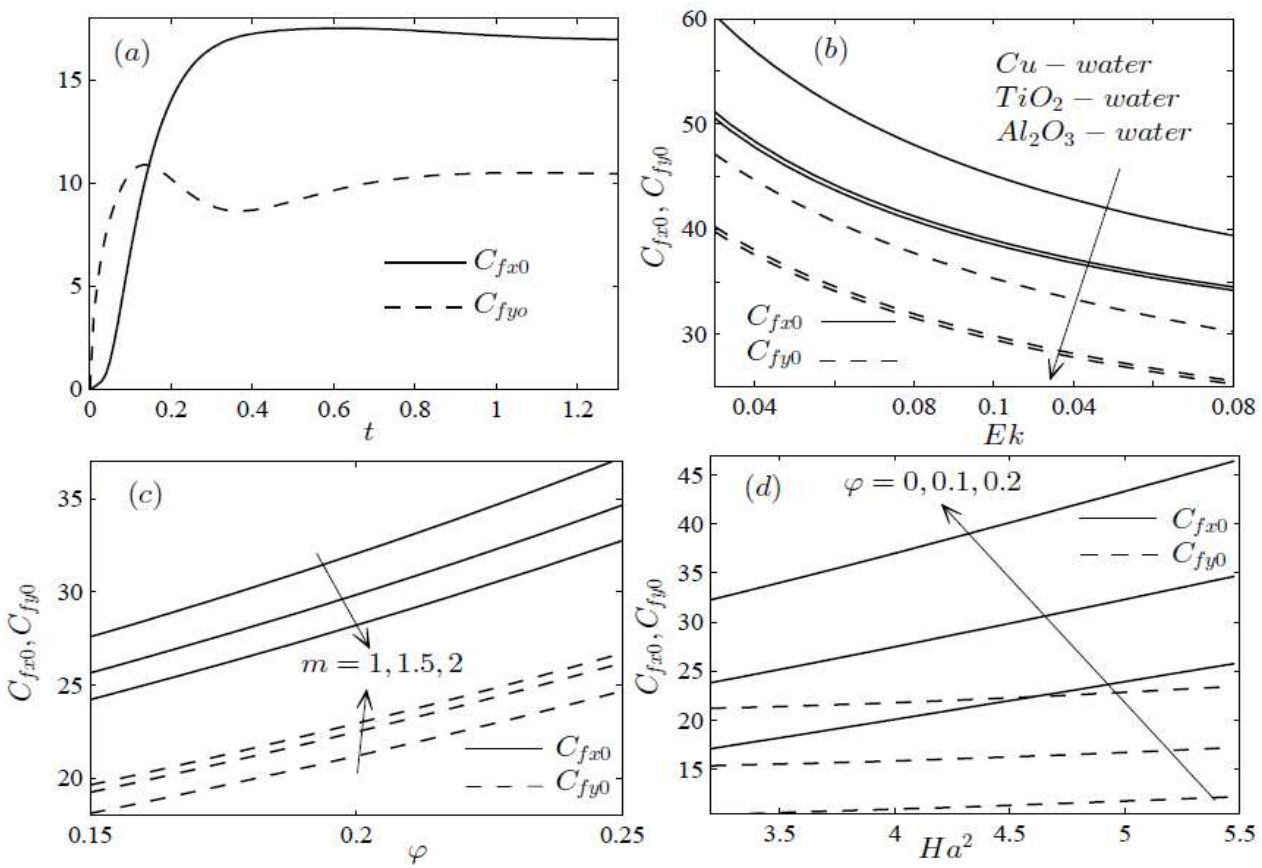

Fig. 10. Skin Friction profiles. 

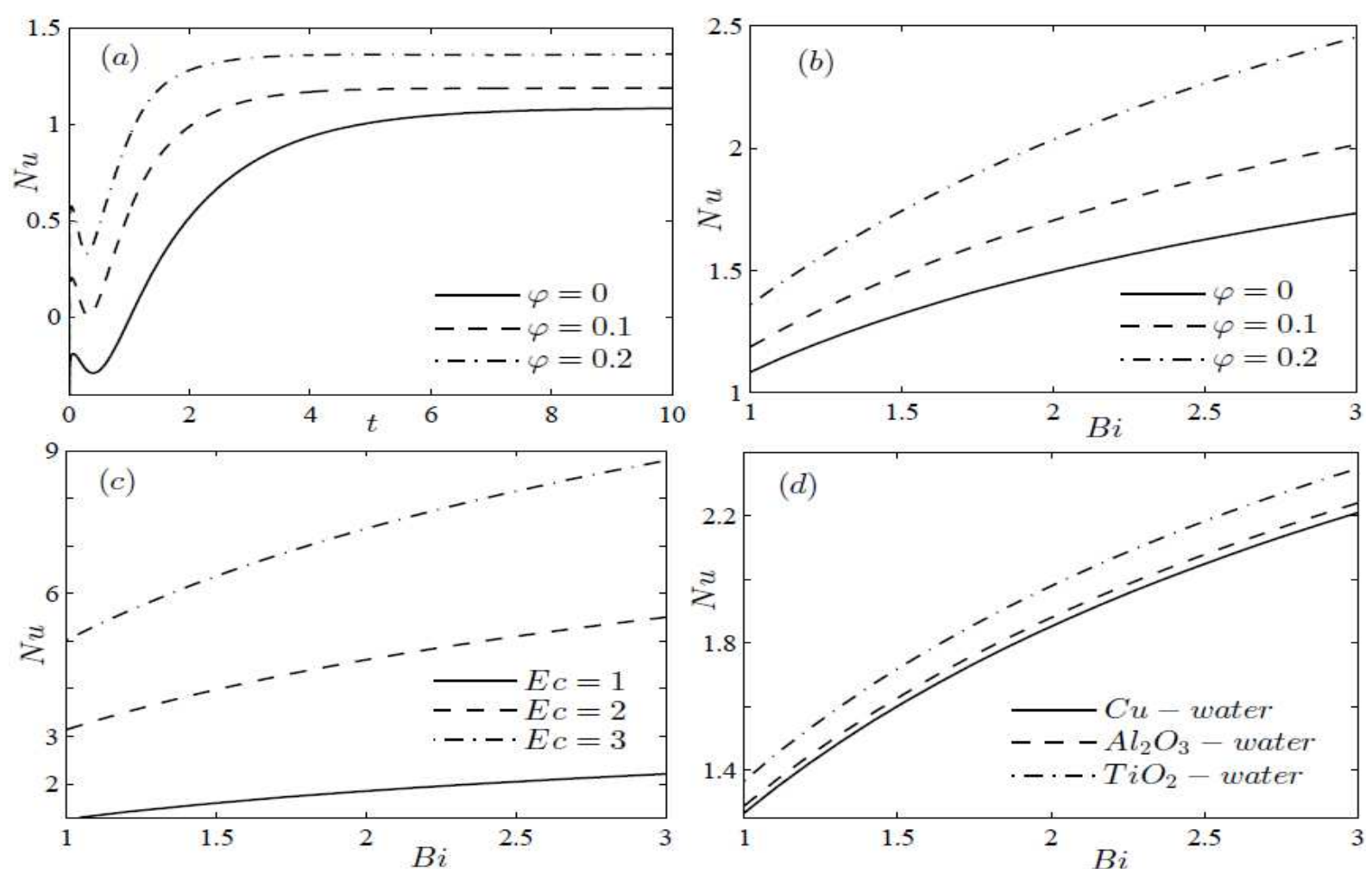

Fig. 11. Nusselt number profiles.
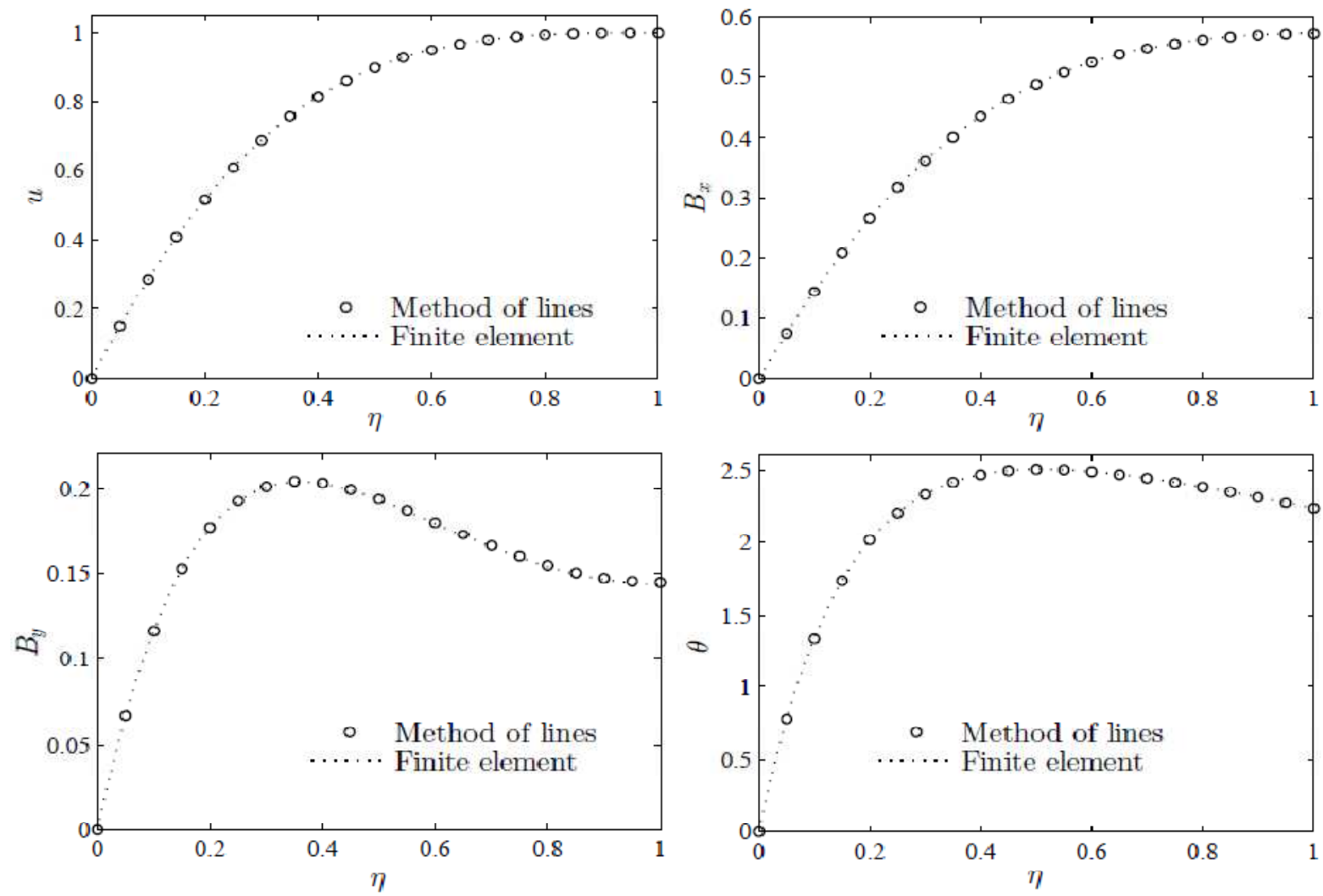

Fig. 12. Numerical comparison.

\section{Conclusion}

We investigate the transient magneto-hydrodynamic flow of nanofluids with Hall current and induced magnetic fields taken into account. The nanofluids are subjected to one dimensional pressure-Couette driven flow. Starting from rest, zero induced magnetic fields and initial temperature, the flow quantities progressively increase (with some oscillations) 
until a steady state is attained. The steady solutions (except temperature) actually come much earlier than that of temperature profiles. We summarize the results by pointing out some significant effects associated with the flow parameters. The temperature increases with $E c, H a, \varphi$ and decreases with $B i, m, E k$. Al2O3-water nanofluid demonstrated the highest induced magnetic field than $\mathrm{Cu}-$ water and $\mathrm{TiO} 2-$-water nanofluids. The primary induced magnetic field is negatively affected when the Hall current parameter is raised but the secondary induced magnetic field is influenced. The heat transfer rate $(\mathrm{Nu})$ is influenced by Ec, $\mathrm{Bi}, \varphi$ while skin friction is mostly influenced by $\varphi$.

\section{References}

[1] O.D. Makinde, Effect of arbitrary magnetic Reynolds number on MHD flows in convergent-divergent channels, International Journal of Numerical Methods for Heat \& Fluid Flow 18(2008) 697-707.

[2] P. Eguia, J. Zueco, E. Granada, D. Patiño, NSM solution for unsteady MHD Couette flow of a dusty conducting fluid with variable viscosity and electric conductivity, Applied Mathematical Modelling 35(2011) 303-316.

[3] S.R. Mishra, S. Jena, Numerical solution of boundary layer MHD flow with viscous dissipation, The Scientific World Journal 2014(2014).

[4] A. Rao, R.S. Raju, S. Sivaiah, Finite element solution of MHD transient flow past an impulsively started infinite horizontal porous plate in a rotating fluid with Hall current, Journal of Applied Fluid Mechanics 5(2012) 105-112.

[5] S.U.S. Choi, Enhancing thermal conductivity of fluids with nanoparticles. In: D. Singer H. Wang, (Eds), Development and Applications of Non-Newtonian Flows, ASME, New York, 1995.

[6] T.G. Motsumi, O.D. Makinde, Effects of thermal radiation and viscous dissipation on boundary layer flow of nanofluids over a permeable moving flat plate, Physica Scripta 86(2012) 045003 .

[7] K.V. Wong, O. De Leon, Applications of nanofluids: current and future, Advances in Mechanical Engineering. 2010(2010).

[8] O.D. Makinde, Effects of viscous dissipation and Newtonian heating on boundary-layer flow of nanofluids over a flat plate, International Journal of Numerical Methods for Heat \& Fluid Flow 23(2013) 1291-1303.
[9] M. Sheikholeslami, M. Gorji-Bandpy, D.D. Ganji, S. Soleimani, Effect of a magnetic field on natural convection in an inclined half-annulus enclosure filled with $\mathrm{Cu}$-water nanofluid using CVFEM, Advanced Powder Technology 24(2013) 980-991.

[10] O.D. Makinde, A. Ogulu, The effect of thermal radiation on the heat and mass transfer flow of a variable viscosity fluid past a vertical porous plate permeated by a transverse magnetic field, Chemical Engineering Communications 195(2008), 1575-1584.

[11] B.I. Olajuwon, Convection heat and mass transfer in a hydromagnetic flow of a second grade fluid in the presence of thermal radiation and thermal diffusion, International Communications in Heat and Mass Transfer 38(2011) 377-382.

[12] W.N. Mutuku-Njane, O.D. Makinde, Combined effect of buoyancy force and Navier slip on MHD flow of a nanofluid over a convectively heated vertical porous plate, The Scientific World Journal 2013(2013).

[13] G.S. Seth, G.K. Mahato, J.K. Singh, Effects of Hall current and rotation on MHD Couette flow of class-II, Journal of International Academy of Physical Sciences 15(2012), 201219.

[14] S.K. Ghosh, O.A Bég, A. Aziz, A mathematical model for magnetohydrodynamic convection Flow in a rotating horizontal channel with inclined magnetic field, magnetic induction and Hall current effects, World Journal of Mechanics 1(2011) 137.

[15] H. Zaman, M.A. Shah, F. Khan, Q. Javed, Effects of Hall current on MHD boundary layer second-order viscoelastic fluid flow induced by a continuous surface with heat transfer, American Journal of Computational Mathematics 4(2014) 143.

[16] H.A. Mintsa, G. Roy, C. T. Nguyen, D. Doucet, New temperature dependent thermal conductivity data for waterbased nanofluids, International Journal of Thermal Sciences 48(2009) 363-371

[17] S. Kakac, A. Pramuanjaroenkij, Review of convective heat transfer enhancement with nanofluids, International Journal of Heat and Mass Transfer 52(2009) 3187-3196.

[18] V. Trisaksri, S. Wongwises, Critical review of heat transfer characteristics of nanofluids, Renewable and Sustainable Energy Reviews 11(2007) 512-523.

[19] J. Buongiorno, Convective transport in nanofluids, Journal of Heat Transfer 128(2006) 240-250.

[20] T.Y. Na, Computational methods in engineering boundary value problems, Academic Press, New York, 1979. 